\title{
Performance of the Pressure Assisted Forward Osmosis-MSF Hybrid Desalination Plant
}

\author{
Daoud Khanafer ${ }^{1}$, Sudesh Yadav ${ }^{1}\left(\mathbb{D}\right.$, Namuun Ganbat ${ }^{1}$, Ali Altaee ${ }^{1, *(\mathbb{D},}$, John Zhou $^{1}$ and Alaa H. Hawari ${ }^{2}$ \\ 1 Centre for Green Technology, School of Civil and Environmental Engineering, University of Technology \\ Sydney, 15 Broadway, Sydney, NSW 2007, Australia; daoud.khanafer@student.uts.edu.au (D.K.); \\ sudesh.yadav@student.uts.edu.au (S.Y.); Namuun.Ganbat@student.uts.edu.au (N.G.); \\ junliag.zhou@uts.edu.au (J.Z.) \\ 2 Department of Civil and Architectural Engineering, Qatar University, Doha P.O. Box 2713, Qatar; \\ a.hawari@qu.edu.qa \\ * Correspondence: ali.altaee@uts.edu.au
}

Citation: Khanafer, D.; Yadav, S.; Ganbat, N.; Altaee, A.; Zhou, J.; Hawari, A.H. Performance of the Pressure Assisted Forward Osmosis-MSF Hybrid Desalination Plant. Water 2021, 13, 1245. https:// doi.org/10.3390/w13091245

Academic Editor: Thomas M. Missimer

Received: 25 February 2021

Accepted: 27 April 2021

Published: 29 April 2021

Publisher's Note: MDPI stays neutral with regard to jurisdictional claims in published maps and institutional affiliations.

Copyright: () 2021 by the authors. Licensee MDPI, Basel, Switzerland. This article is an open access article distributed under the terms and conditions of the Creative Commons Attribution (CC BY) license (https:// creativecommons.org/licenses/by/ $4.0 /)$.

\begin{abstract}
An osmotically driven membrane process was proposed for seawater pretreatment in a multi-stage flashing (MSF) thermal plant. Brine reject from the MSF plant was the draw solution (DS) in the forward osmosis (FO) process in order to reduce chemical use. The purpose of $\mathrm{FO}$ is the removal of divalent ions from seawater prior the thermal desalination. In this study, seawater at $80 \mathrm{~g} / \mathrm{L}$ and $45 \mathrm{~g} / \mathrm{L}$ concentrations were used as the brine reject and seawater, respectively. The temperature of the brine reject was $40^{\circ} \mathrm{C}$ and of seawater was $25^{\circ} \mathrm{C}$. Commercial thin-film composite (TFC) and cellulose triacetate (CTA) membranes were evaluated for the pretreatment of seawater in the $\mathrm{FO}$ and the pressure-assisted $\mathrm{FO}(\mathrm{PAFO})$ processes. Experimental results showed $50 \%$ more permeation flux by increasing the feed pressure from 1 to 4 bar, and permeation flux reached $16.7 \mathrm{~L} / \mathrm{m}^{2} \mathrm{~h}$ in the PAFO process with a TFC membrane compared to $8.3 \mathrm{~L} / \mathrm{m}^{2} \mathrm{~h}$ in the PAFO process with CTA membrane. TFC membrane experienced up to $15 \%$ reduction in permeation flux after cleaning with DI water while permeation flux reduction in the CTA membrane was $>6 \%$. The maximum recovery rate was $11.5 \%$ and $8.8 \%$ in the PAFO process with TFC and CTA membrane, respectively. The maximum power consumption for the pretreatment of seawater was $0.06 \mathrm{kWh} / \mathrm{m}^{3}$ and $0.1 \mathrm{kWh} / \mathrm{m}^{3}$ for the PAFO process with a TFC and CTA membrane, respectively.
\end{abstract}

Keywords: forward osmosis (FO); desalination; FO-MSF hybrid system; pressure assisted FO (PAFO); membrane filtration

\section{Introduction}

Seawater desalination has become a strategic source of clean water worldwide and specifically in the area of the Middle East, where the natural resources are limited [1,2]. Reverse Osmosis (RO) represents the primary membrane technology for desalination, while thermal technologies are mainly the Multi-Stage Flushing (MSF) and, to a less extent, the Multi-Effect Distillation (MED) [3-5]. Despite RO being more energy-efficient [6], thermal desalinations are still prominent in the Middle East especially in the Gulf countries due to their high performance in treating FS of high salinity and low-quality seawater, reliability, and no need for intensive pretreatment of FS $[5,7,8]$. Hence, thermal desalination is responsible for $70 \%$ of the total freshwater supply in the Middle East [7]. Besides the fact that the thermal desalination plants produce high-quality freshwater they suffer from scale formation on the heat exchangers, which is one of the drawbacks that affect the efficiency of the desalination process [5]. At elevated temperatures, alkaline scales such as calcium carbonate $\left(\mathrm{CaCO}_{3}\right)$ and non-alkaline such as calcium sulphate $\left(\mathrm{CaSO}_{4}\right)$ and magnesium sulphate $\left(\mathrm{MgSO}_{4}\right)$ deposit on the heat exchangers causing a reduction in the heat transfer rate and therefore lower the plant efficiency. Scale precipitation adversely impacts the performance of thermal desalination plants and the energy requirements for 
desalination $[9,10]$. Periodic cleaning and antiscalants are often applied to minimize scaling problems; however, they cannot always prevent it [7], particularly non-alkaline scale in the MSF plants, which requires regular shutting down of the MSF plant for cleaning [11]. Recently, FO was suggested for the pretreatment of seawater to the MSF plants for the removal of multivalent ions, causing scale problems. When coupling FO process with the MSF, the MSF brine concentrate will be used as the draw solution (DS) for the FO process in order to reduce the operation cost [12]. The feed water in the FO process is seawater that would be pretreated for the removal of divalent ions (Figure 1). The purpose of the FO process is to dilute the concentration of divalent ions in the brine reject before recycling to the MSF unit to minimize/prevent the precipitation of magnesium sulphate and calcium sulphate on the surface of heat exchangers tubes. Previous research revealed the viability of applying the FO process in minimizing scale problems and increasing the top brine temperature (TBT) in the MSF plants [12,13]. It is noticeable that research on the FO technology for the treatment of seawater to MSF/MED systems is scarce, and more work is required to understand the role of membrane materials and applied feed pressure on the FO process [2].

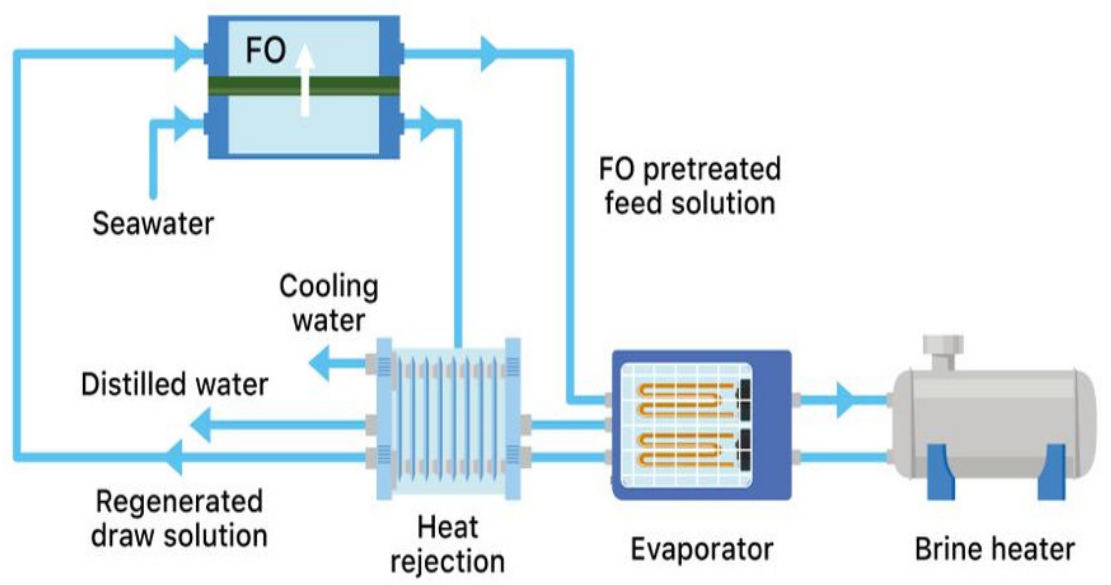

Figure 1. Schematic diagram illustrating the FO pretreatment of seawater to the MSF plant.

Driven by the osmotic pressure gradient across the membrane, FO was introduced as a pretreatment process in the cycle of the MSF desalination plant [12]. The innovation in the model proposed is that the brine rejected from the MSF plants plays the role of DS in the FO process and the seawater in its turn is the FS. The outcome is promising in minimizing the concentration of multivalent ions in the feed water to the MSF plant. The diluted brine will return to the MSF system as a lower salinity FS with the potential to reduce scale deposition and allows the MSF plant to work at elevated TBT. Moreover, the proposed FO-MSF system might solve the issue of hot brine rejection to the sea and reduce the seawater intake [12]. The FO-MSF system was theoretically designed, and its feasibility has investigated to reveal a potential reduction in $\mathrm{Ca}^{2+}, \mathrm{Mg}^{2+}$, and $\mathrm{SO}_{4}{ }^{2-}$ ions concentrations.

Although theoretical studies underpinned the potential of the FO-MSF system, there were only a few experimental studies in this field. Thabit et al. [13] studied the efficiency of the FO technology for seawater treatment using cellulose triacetate $\mathrm{FTSH} 2 \mathrm{O}^{\mathrm{TM}}$ membrane and actual brine reject DS at $40{ }^{\circ} \mathrm{C}$. The FO membrane tested in the PRO mode (DS-AL (Active Layer)) achieved $22.3 \mathrm{~L} / \mathrm{m}^{2} \mathrm{~h}$ permeation flux exceeded and $8.5 \%$ dilution of the DS brine at the end of the experiment. The outcomes of the study formed a foundation that needs building upon with more experiments to deeper investigate and evaluate the adoption of the FO-MSF system in the Middle East. The type of membrane materials and operating modes also affects membrane fouling propensity and permeation flux [14,15]. To understand the impact of membrane materials, researchers investigated the impact of membrane materials on the efficiency of the FO process [2,16,17]. A study investigated the 
efficiency of the FO technology in CTA and TFC membranes, it revealed that permeation flux in the TFC was greater than that in the CTA membrane [16]. Previous work also examined the impact of operating parameters on the efficiency of the FO process. A study by Alaa et al. [18] evaluated the impact of the temperatures of the stream solutions on the FO process revealed that permeation flux could be increased when the temperature of the DS increased from 20 to $26^{\circ} \mathrm{C}$. Although the permeation flux in the FO technology is mainly driven by the osmotic pressure gradients across the membrane, several studies tested pressure-assisted FO (PAFO) to improve the permeation flux and tackling the influence of concentration polarization (CP) on the membrane $[19,20]$. The concept of PAFO consists of applying low feed pressure to increase the permeation flow under the effect of both osmotic and hydraulic pressures [21] since that the AL-FS orientation is known for causing severe dilutive internal concentration polarization (ICP). A study by Jamil and co-workers evaluated the feasibility of PAFO for the treatment of RO brine and results showed $2 \%$ and $29 \%$ increase in the permeation flux by applying 2 and 4 bar, respectively [22].

The current study evaluated the performance of the PAFO process in the pretreatment of seawater to the MSF plant owing to its energy efficiency [23]. A seawater brine of $80 \mathrm{~g} / \mathrm{L}$ concentration and $40{ }^{\circ} \mathrm{C}$ was the DS in the FO process to resemble the concentration and temperature of the MSF brine reject in the Middle East. The FS in the FO membrane was seawater of a $45 \mathrm{~g} / \mathrm{L}$ concentration and $25^{\circ} \mathrm{C}$ that represents the conditions of seawater in the Middle East. Additionally, there is no information available yet on the influence of membrane materials on the performance of the FO-MSF system, knowing that both TFC and CTA FO membranes are commercially available. Porifera TFC and FTSH2O ${ }^{\text {TM }}$ CTA membranes were tested to find out the influence of membrane materials on the efficiency of the FO process and permeation flux recovery after membrane cleaning. Both membranes were tested in the AL-FS and AL-DS modes or orientations using 0 to 4 bar feed pressure since previous studies showed discrepancies in the process efficiency when it operates under different membrane orientations $[13,24]$. The permeation flow, rejection rate of $\mathrm{Ca}^{2+}$, $\mathrm{Mg}^{2+}$, and $\mathrm{SO}_{4}{ }^{2-}$ ions, and the process recovery rate were calculated in the $\mathrm{FO}$ and the PAFO processes for TFC and CTA membranes. The study also estimated the specific power consumption for the CTA and the TFC membrane.

\section{Methodology}

\subsection{FO Membranes and Characterization}

Porifera TFC and FTSH2O ${ }^{\mathrm{TM}}$ CTA membranes were implemented in this study to test their performance under different operating parameters. As shown in Table 1 and referring to the manufacturer guideline, the TFC membrane from Porifera has a structural parameter $(S)$ of 344 microns. The membrane can tolerate pressure up to $12.41 \mathrm{bar}, 40^{\circ} \mathrm{C}$ feed temperature, and salt rejection capability up to $90 \%$ [25]. Similarly, the datasheet from $\mathrm{FTSH}_{2} \mathrm{O}$ summarised the characteristics of the CTA presented in Table 1 [26]. This membrane can tolerate up to $50^{\circ} \mathrm{C}$ feed temperature and hydraulic pressure of 5 bar.

Table 1. Characteristics of Porifera and $\mathrm{FTSH}_{2} \mathrm{O}$ membranes.

\begin{tabular}{ccc}
\hline Parameter & Porifera (TFC) & FTSH2O $^{\text {TM }}$ (CTA) \\
\hline Membrane chemistry & Thin-film composite & Cellulose triacetate \\
$\mathrm{A}\left(\mathrm{L} / \mathrm{m}^{2} \mathrm{~h}\right.$. bar $)$ & 2.1 & 0.69 \\
$\mathrm{~B}\left(\mathrm{~L} / \mathrm{m}^{2} \mathrm{~h}\right)$ & 1.2 & 0.34 \\
$\mathrm{~S}(\mu \mathrm{m})$ & 344 & 707 \\
Contact angle active layer $\left(^{\circ}\right)$ & $68.5 \pm 0.7$ & $68.1 \pm 1$ \\
Contact angle support layer $\left(^{\circ}\right)$ & $53.9 \pm 2$ & $60.2^{\circ} \pm 0.5$ \\
Zeta potential $(\mathrm{mV})$ & $-41.9 \pm 2.44$ & $-12.8 \pm 1.18$ \\
\hline
\end{tabular}


In Table 1, A represents the water permeability constant, B represents the coefficient of solute permeability, and $S$ is the membrane structural parameter. A was calculated using the following expression:

$$
A=\frac{J_{w}}{\Delta P}
$$

where $J_{w}$ is the water flux in $\mathrm{L} / \mathrm{m}^{2} \mathrm{~h}$ and $\Delta P$ is the pressure gradient across the membrane in bar. In its turn, $\mathrm{B}$ was also calculated using the following expression:

$$
B=\frac{\left(1-R_{j}\right)}{R_{j}} J_{w}
$$

where $R_{j}$ is the rejection rate of the membrane and $J_{w}$ is the water flux. The values of $\mathrm{A}$ and $\mathrm{B}$ presented in this paper were also reported in previous studies [26]. Wettability measurements and hydrophilic behaviour of the virgin Porifera TFC and $\mathrm{FTSH}_{2} \mathrm{O}$ CTA membranes were investigated by measuring the contact angle using the sessile drop method at various places on the same membrane, and it is measured using FACE Automatic Interfacial Tensiometer (Japan) [27]. Images of water contact angle measurement are represented in Figure 2. Surface morphology of the used and cleaned membranes for ALDS direction was obtained using a scanning electron microscope (SEM, Zeiss Supra 55VP). In addition, SEM was performed to locate and analyse the fouling materials. SEM images were taken on fouled and washed membranes in both AL and SL. All the membranes were washed with deionized (DI) water and subsequently dried in a vacuum chamber before characterization. Zeta potential measurements were carried out for virgin Porifera TFC and $\mathrm{FTSH}_{2} \mathrm{O}$ CTA membranes using Malvern instruments. The wettability of membranes measures the wetting angle between the interface of the surface of the water and the outline of the membrane surface. The active layer (AL) of Porifera TFC and $\mathrm{FTSH}_{2} \mathrm{O}$ CTA membrane shows almost an equal water contact angle $~ 68.5$ and 68.1, respectively, (Figure 2). As for the support layer, Porifera TFC showed lower water contact angle, $\sim 53.9$, than $\mathrm{FTSH}_{2} \mathrm{O}$ CTA membrane, $\sim 60.2$.

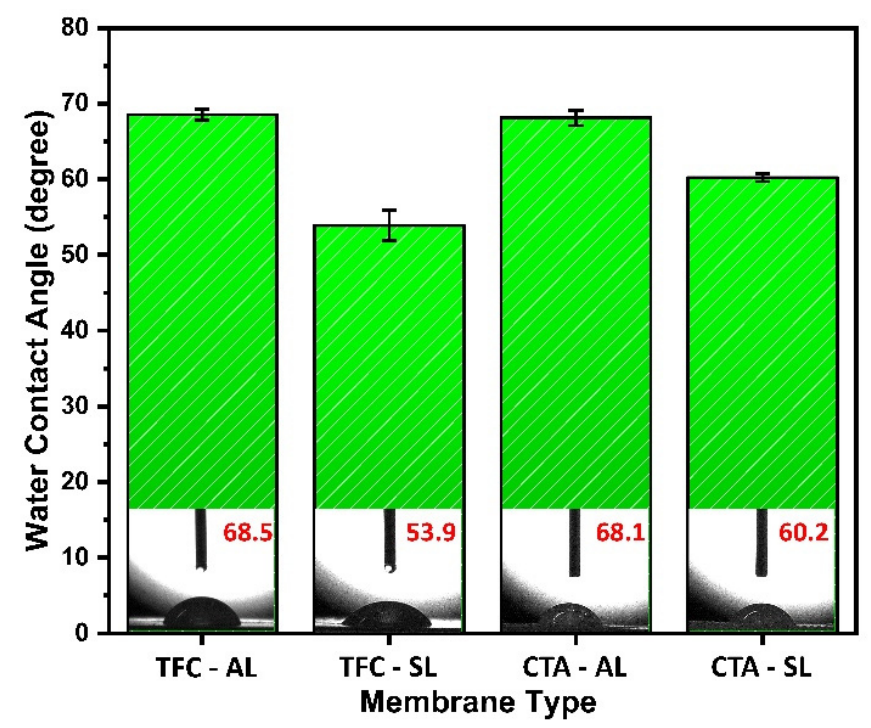

Figure 2. Water contact angle for virgin Porifera TFC and FTSH2O ${ }^{\mathrm{TM}} \mathrm{CTA}$ membranes.

\subsection{Feed and Draw Solutions}

In this study, fresh seawater was collected from the Sydney, Australia, area with a salinity of $32 \mathrm{~g} / \mathrm{L}$ and concentrated by heating to increase its concentration to the level of brine reject and seawater from the MSF plants. In all experiments, the concentration of the FS was $45 \mathrm{~g} / \mathrm{L}$ and of the DS was $80 \mathrm{~g} / \mathrm{L}$. Additionally, the temperature of FS was $25^{\circ} \mathrm{C}$ and of the DS was $40^{\circ} \mathrm{C}$ to resemble the temperature of brine reject [13]. As a primary step, 
seawater was stored in containers and left for at least two days for the large particles to settle. Table 2 shows the compositions and characteristics of the FS and the DS used in the experimental work.

Table 2. Characteristics of FS and DS used in the FO process.

\begin{tabular}{cccc}
\hline Ion/Parameter & FS $\mathbf{( 4 5} \mathbf{~} / \mathbf{L})$ & DS $\mathbf{( 8 0} \mathbf{g} / \mathbf{L})$ & Measuring Instrument \\
\hline $\mathrm{Ca}^{2+}(\mathrm{ppm})$ & 855.2 & 1040.9 & 7900 ICP-MS \\
$\mathrm{Mg}^{2+}(\mathrm{ppm})$ & 1895.3 & 2199.6 & 7900 ICP-MS \\
$\mathrm{SO}_{4}^{2-}(\mathrm{ppm})$ & 3171.6 & 6566 & DIONEX AS-AP \\
$\mathrm{Cl}^{-}(\mathrm{ppm})$ & 9832 & $22,351.6$ & 7900 ICP-MS \\
$\mathrm{Na}^{+}(\mathrm{ppm})$ & $16,372.9$ & $19,151.6$ & 7900 ICP-MS \\
$\mathrm{K}^{+}(\mathrm{ppm})$ & 692.9 & 872.3 & 7900 ICP-MS \\
$\mathrm{TDS}(\mathrm{g} / \mathrm{L})$ & 45.1 & 80.2 & HQ14d Conductivity \\
Conductivity $(\mathrm{mS} / \mathrm{cm})$ & 68.9 & 106.7 & HQ14d Conductivity \\
$\mathrm{pH}$ & 8.0 & 8.35 & HQ40d multi \\
Turbidity (NTU) & 1.47 & 2.43 & 2100P Turbidimeter \\
\hline
\end{tabular}

\subsection{FO System Components}

FO membranes were placed in the CF042A-FO Cell manufactured by Sterlitech. This clear cast acrylic cube-shaped cell is a filtration unit of $5 \times 4 \times 3.25$-inch exterior dimensions and includes a $42 \mathrm{~cm}^{2}\left(6.5 \mathrm{inch}^{2}\right)$ membrane area. The cell can tolerate $88^{\circ} \mathrm{C}$ maximum temperature and 27.6 bar of hydraulic pressure. The system was provided with 2 flow meters F-550 (Blue-White Industries Ltd, Sterlitech, Washington, DC, USA) connected on each side of the cell to measure the flow rates of the FS and DS. The system is furnished with pressure gauges (USG U.S. Gauge) with a range between 0 and 4 bar to measure the hydraulic pressure on the FS and DS. Water circulation in the system was maintained by using two pumps manufactured by Cole-Parmer providing up to 5 bar. The conductivity of solutions, as well as the TDS and the salinity, were measured using HQ 14d portable conductivity and TDS meter (HACH, Sydney, Australia). The variation in the FS weight was monitored using a digital scale balance and forwarded to a computerized system to calculate the permeation flux. Figure 3 shows an illustration of the FO unit used in the experimental work.

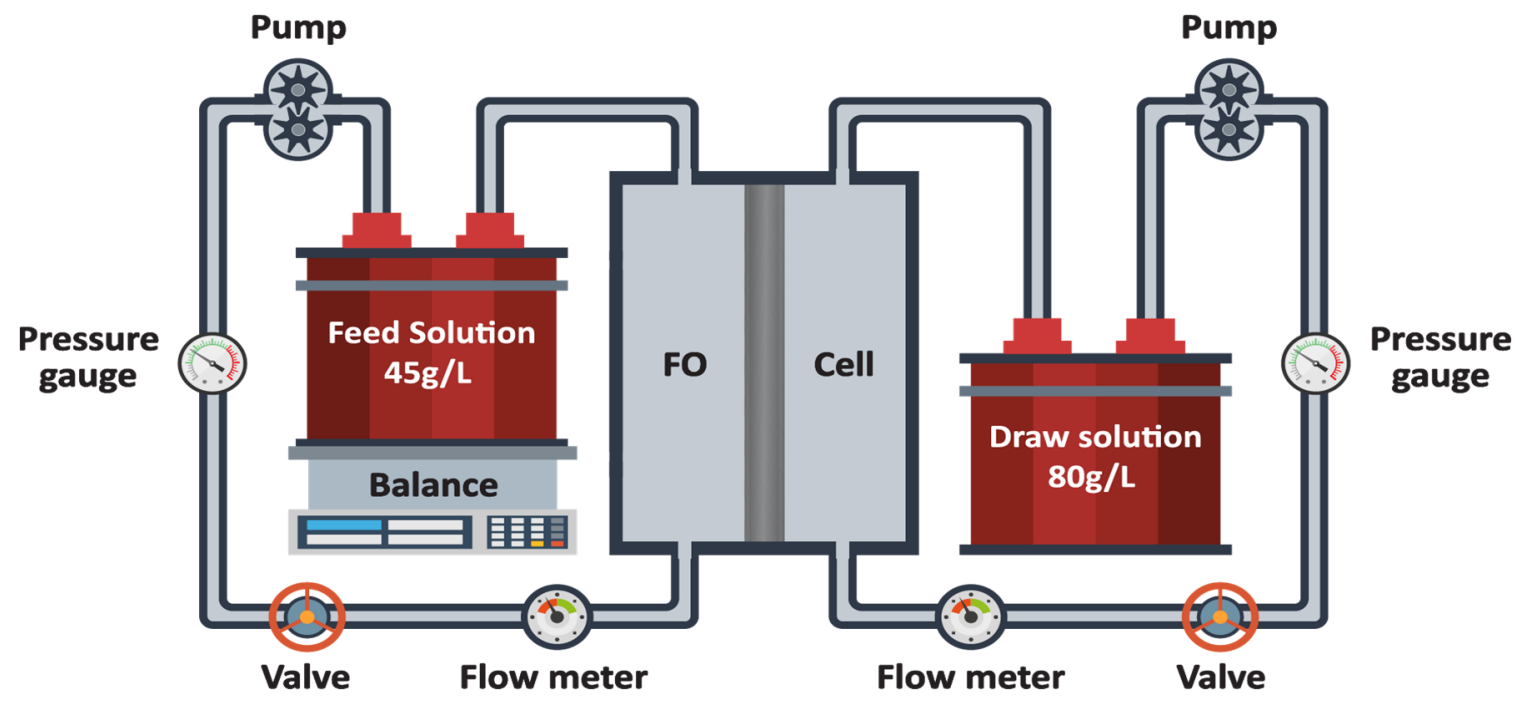

Figure 3. FO bench-scale unit configuration used in the FO experiments. 


\subsection{Experimental Work}

Each run of the FO process lasted for $5 \mathrm{~h}$, and each membrane was washed with DI water for $30 \mathrm{~min}$ at the end of the process, before using it again in the next run. For all FO processes, permeation flux collected in the first $10 \mathrm{~min}$ was discarded until the membrane filtration process was stabilized. The first set of FO tests was designed to calculate permeation flux at hydraulic pressure gradient equals to zero $(\Delta \mathrm{P}=0)$ then a feed pressure in a range of 1 to 4 bar was applied in the PAFO process. Divalent ions, $\mathrm{Ca}^{2+}, \mathrm{Mg}^{2+}$, and $\mathrm{SO}_{4}{ }^{2-}$ concentrations were measured at the beginning and end of each experiment.

Permeation flux in LMH was calculated after measuring the variation of the weight of the FS during the process according to the following equation [28]:

$$
J_{W}=\frac{\Delta W}{A \times \Delta t}
$$

$\Delta W$ is the difference in the weight of FS in $\mathrm{kg}$, A represents the membrane area in $\mathrm{m}^{2}$, and $\Delta t$ is time interval in hours (h).

At the beginning and the end of each FO run, the concentrations of $\mathrm{Ca}^{2+}$ and $\mathrm{Mg}^{2+}$ in the DS was measured using an ion chromatography machine 7900 ICP-MS provided by Agilent technologies. The concentrations of $\mathrm{SO}_{4}{ }^{2-}$ were measured using Dionex VWDIC manufactured by HPIC. These three ions were the only ions studied and measured in this study as they are accountable for the non-alkaline scale development in the MSF plants in the form of $\mathrm{MgSO}_{4}$ and $\mathrm{CaSO}_{4}$ [29]. Reducing the concentration of these ions in the DS using the FO process will help in controlling scale formation and depositions, using a diluted FS in the MSF process [18].

\section{Results and Discussion}

\subsection{Impact of Membrane Materials and Orientations \\ 3.1.1. Permeation Flux}

The impact of applying hydraulic pressures on the FS side was investigated in terms of permeation flux. The first set of experiments measured permeation flux at feed pressure between 0 and 4 bar for $5 \mathrm{~h}$ in the AL-FS mode, and both membranes (TFC \& CTA) were tested for this orientation. In the PAFO experiments, a feed pressure between 1 and 4 bar with 1 bar interval was applied to the FS. The temperature of the DS and the FS was $40{ }^{\circ} \mathrm{C}$ and $25{ }^{\circ} \mathrm{C}$, respectively, which represent the temperature of the brine reject from the MSF plant and the seawater in the Middle East [13]. Figures $4 \mathrm{~A}$ and $5 \mathrm{~A}$ present the variation in the permeation flux throughout $5 \mathrm{~h}$ tests at different applied pressures on the FS in the AL-FS mode for the TFC and the CTA membranes, respectively. Results also show that permeation flux at 0 bar was around 7.4 Lmh compared to $14.8 \mathrm{Lmh}$ at 4 bar for the TFC FO membrane and $6.4 \mathrm{Lmh}$ and $8 \mathrm{Lmh}$ at 0 and 4 bar, respectively, for the CTA FO membrane. Indeed, increasing the feed pressure from 0 to 4 bar resulted in a $50 \%$ more permeation flux in the TFC membrane and 25\% more permeation flux in the CTA membrane. The thicker support layer of CTA membrane led to an intense ICP, which reduced permeation flux compared to the TFC membrane that has 50\% thinner support layer (Table 1). Generally, results show a drop in the permeation flux over time because of the concentration of the FS and the dilution of the FS, which caused a sharp drop in the osmotic driving force and therefore lowered the permeation flux [13]. There is a remarkable decline in permeation flux over time, particularly in the PAFO test performed with a TFC membrane. The decline in the permeation flux when using TFC was quick in the first $30 \mathrm{~min}$ and became steady to the end of the experiments. The drop in the permeation flux in the CTA membrane was gradual throughout the $5 \mathrm{~h}$ tests. For example, there was $22.6 \%$ and $19.9 \%$ reduction in the permeation flux in the FO tests with TFC and CTA membranes, respectively. Indeed, there was $65 \%$ and $27 \%$ decrease in the permeation flux in the PAFO tests at 4 bar feed pressure with the TFC and CTA membranes, respectively. This decrease in permeation flux is probably due to the higher permeation flux in the TFC membrane that caused a sharp fall in the osmotic driving force in the PAFO tests. The TFC membrane from Porifera 
achieved higher permeation flux in the FO and PAFO tests in comparison with the CTA membrane, knowing that higher permeation flux was recorded in the PAFO tests. The results suggested that higher dilution of the brine reject (DS) would be accomplished in the PAFO test using Porifera TFC membrane in the AL-FS orientation (Figure $4 \mathrm{~A}$ ).

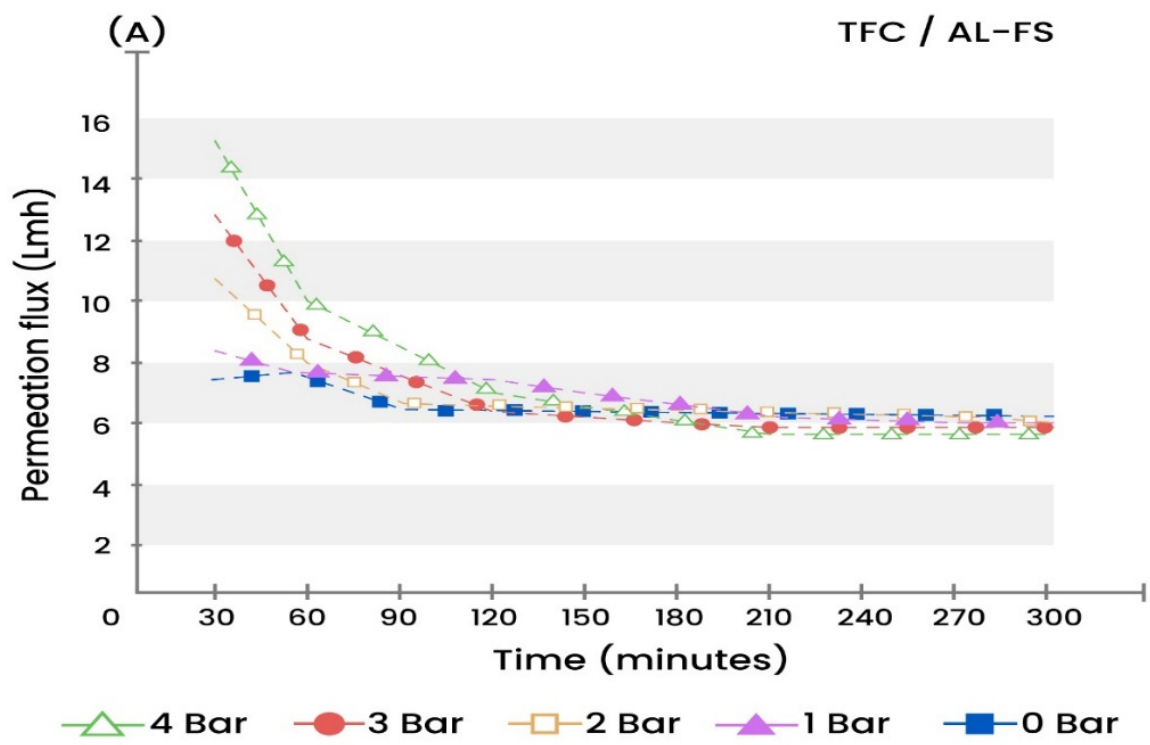

(B)

TFC / AL-DS

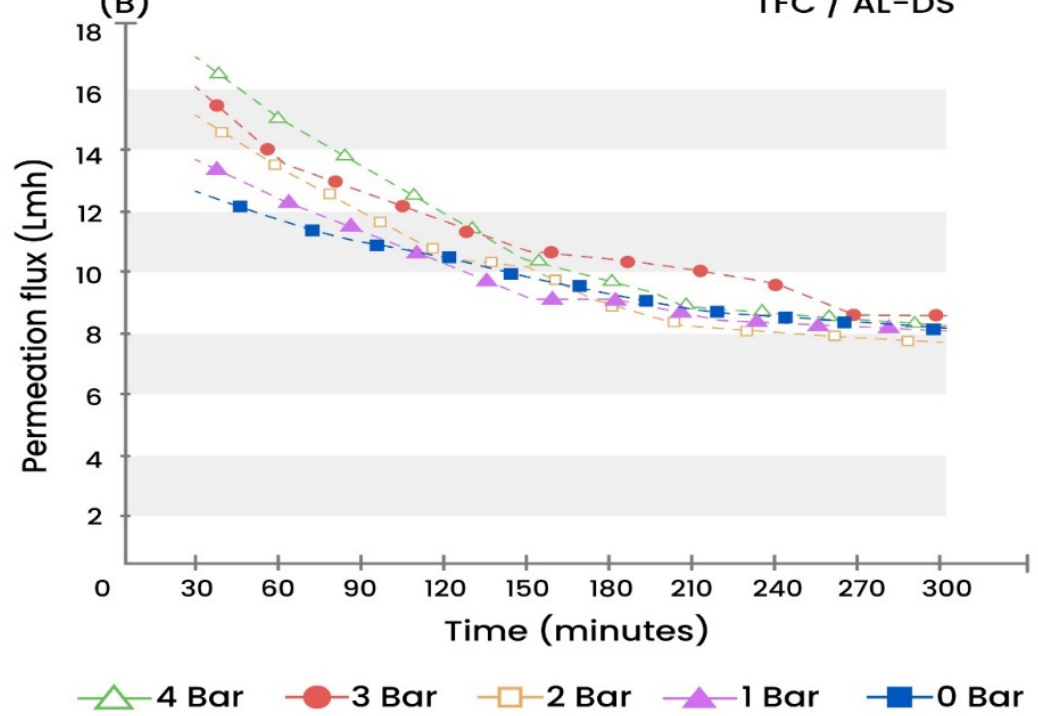

Figure 4. Permeation flux of the FO process over the operating time at applied hydraulic pressures between 0 and 4 bar using TFC membrane in (A) AL-FS and (B) AL-DS orientations. 

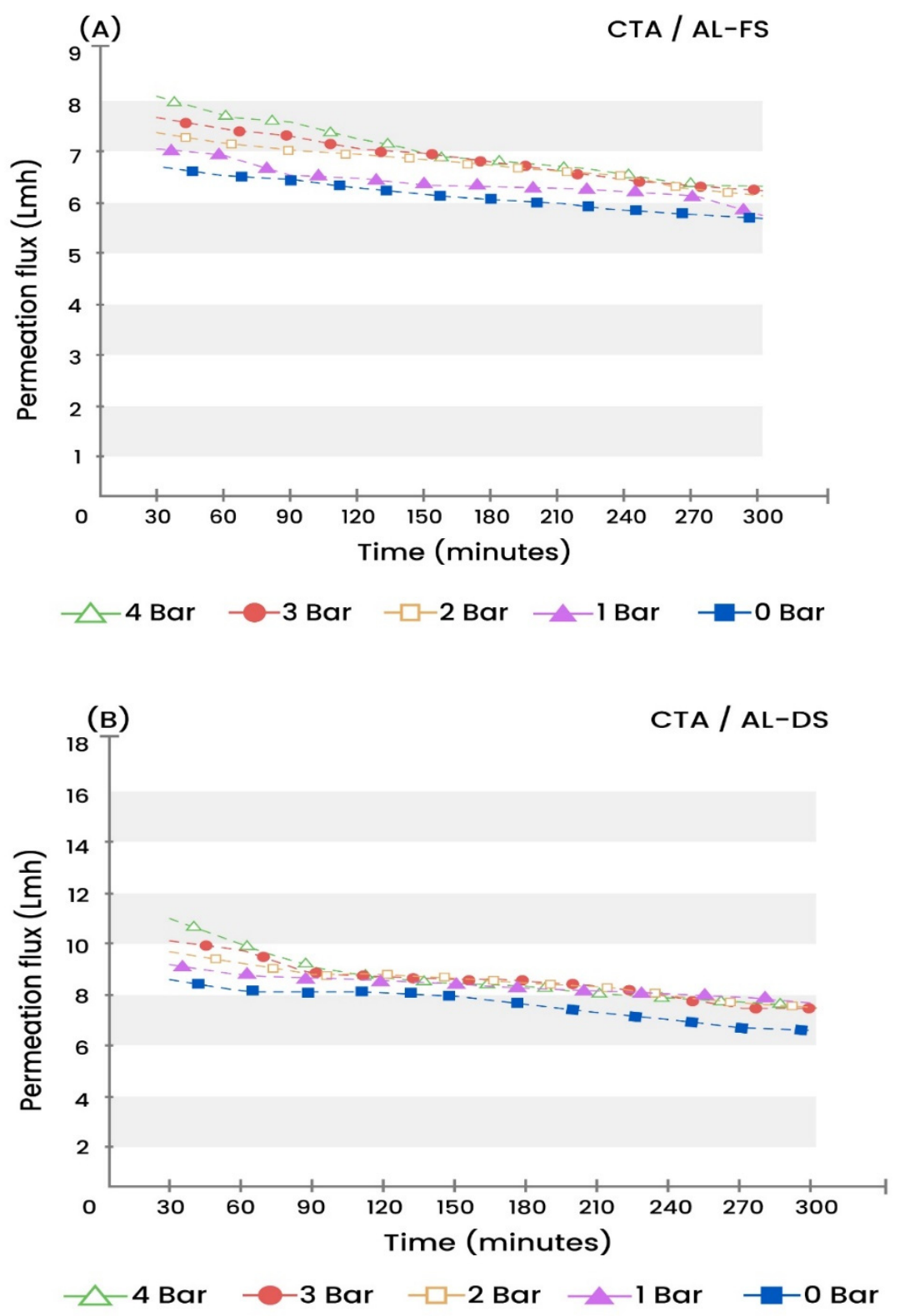

Figure 5. Change of permeation flux with time at different applied pressures using CTA membrane, (A) AL-FS and (B) AL-DS orientations.

In the next set of experiments and under the same conditions, both types of membranes were tested with AL facing the DS and results are presented in Figures $4 \mathrm{~B}$ and $5 \mathrm{~B}$, respectively. These two graphs illustrated the profile of permeation flux in the FO and PAFO tests when the AL-DS mode was applied using TFC and CTA membranes. What is noticeable on a large scale is that a greater permeation flux was achieved in all experiments tested in the AL-DS mode in comparison with the AL-FS operating mode. According to Figure 4A,B, permeation flux in the TFC membrane tested in the AL-FS at 0 bar feed pressure was $7.4 \mathrm{Lmh}$. In contrast, permeation flux was $12.4 \mathrm{Lmh}$ in the membrane tested in the AL-DS. Permeation flux increased by $67 \%$ by altering the membrane mode from the AL-FS to the AL-DS, indicating that more permeation flux and dilution of the brine reject DS was achieved. For the PAFO process at 4 bar feed pressure using TFC membrane, the permeation flux in the Al-FS direction was $14.9 \mathrm{Lmh}$ while it was $16.7 \mathrm{Lmh}$ in the PRO mode, recording more than a $12 \%$ increase in the permeation flux after changing the membrane orientation. For the CTA membrane at 0 bar, there was a $29 \%$ increase in permeation flux by altering the orientation of the membrane from the AL-FS to the AL-DS 
mode (Figure 5A,B). In contrast, there was $34 \%$ more permeation flux in the CTA membrane operating at 4 bar due to altering the orientation from the AL-FS to the AL-DS mode. The results are compatible with previous studies in which FO membrane operating in the PRO mode exhibited greater permeation flux; there was an agreement in these studies that $\mathrm{CP}$ is lower and more controllable in the AL-DS mode [17,18,29-31].

Furthermore, permeation flux was higher in all the experiments using TFC membrane compared to the permeation flux when CTA membranes were used. For example, TFC membrane tested in the AL-FS (Figure $4 \mathrm{~A}$ ) at 0 bar exhibited $83 \%$ more permeation flux in comparison with the CTA membrane tested in the AL-FS direction (Figure 5A). Results also showed that at 4 bar feed pressure, the permeation flux in the TFC membrane tested in the AL-DS direction was 54\% more than that in the CTA membrane tested under the same operating conditions. The reason for this is ascribed to the hydrophilicity of the TFC membrane and its thinner support layer (Table 1), which led to a higher permeation flux in the TFC membrane. Another probable reason for higher permeation flux in the TFC membrane in AL-DS is the higher hydrophilicity of its support layer that promoted the permeation and diffusion of the FS to the DS (Figure 2).

Reduction in the permeation flux due to membrane fouling was evaluated for both membranes and under different operational parameters to determine the most efficient type of membrane for the FO-MSF system. In Figure 6 the calculated average permeation flux was presented at 0 to 4 bar feed pressure for both TFC and CTA membranes and in the AL-FS and AL-DS orientations. For the TFC membrane, results show that a maximum average permeation flux of $9.57 \mathrm{Lmh}$ was achieved at 4 bar hydraulic pressure in the AL-DS direction. Under the same operating conditions, the maximum reported average permeation flux of the CTA membrane was $8.4 \mathrm{Lmh}$, this $12 \%$ less than the average permeation flux achieved in the TFC membrane. For the TFC and CTA membrane operating at 4 bar in the AL-FS orientation, there was $8.6 \%$ difference in the average permeation flux in favour of the TFC membrane. Comparing to the AL-DS mode, the difference in the average permeation flux between the TFC and CTA membrane working in the AL-FS mode was lower. Additionally, this was caused by the complexity of the ICP phenomenon, which affected the driving force across the membrane despite the thinner structural parameter of the TFC membrane. In general, permeation flux declined more rapidly in the PAFO process due to the greater permeation flux, which caused a steep decline in the osmotic pressure. Practically, a faster decline in the osmotic driving force requires fewer FO modules and this will reduce the capital cost for seawater pretreatment by the FO process.
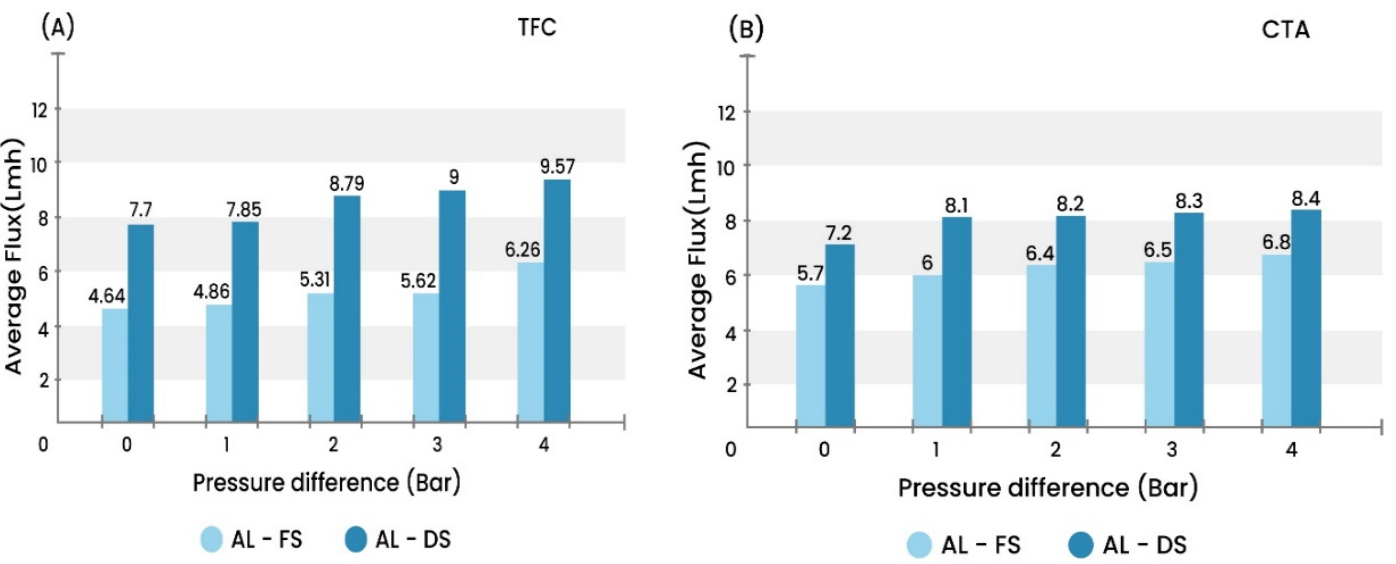

Figure 6. The average membrane flux calculated at different applied pressures of FO process using (A) TFC membrane and (B) CTA membrane in both orientations, AL-FS and AL-DS. 


\subsubsection{Flux Reduction}

Each used membrane was washed for 30 min with DI water at the end of the first test and reused in another run. Then, permeation flux was estimated at the end of the second test to investigate the reduction in the permeation flux due to irreversible fouling of the membrane. Losses in the permeation flux before and after cleaning with a DI water are attributed to the membrane fouling that cannot be removed by simple cleaning with DI water. It is worth mentioning that the DS and FS were not pre-treated before the FO process, and hence fouling would happen on the active and support layer of the membrane. Table 2 shows that the turbidity of the DS and the FS are 2.43 and 1.47 NTU, respectively. It is expected that the fouling layer on the FS side might be denser due to the build-up of foulants on the membrane surface by the convective flow. In contrast, permeation flow from towards the DS side will remove loosely attached fouling materials away from the surface, in a mechanism similar to that in a backwash cleaning. Figure 7A,B show the reduction of permeation flux in the FO experiment using TFC and CTA membranes, respectively. In the case of TFC membrane, the reduction in the permeation flux in the FO mode was $5.2 \%$ at 0 bar feed pressure and increased to $6.9 \%$ at 4 bar feed pressure (Figure 7A). For TFC membrane operating in the PRO mode, the reduction in the permeation flux was $14.6 \%$ in the PAFO test at 4 bar feed pressure and $10.4 \%$ in the FO test. Apparently, FO tests performed in the PRO mode experienced a higher reduction in the permeation flux, and that was due to the poor mixing inside the support layer, reducing the effectiveness of the cleaning process. It is also observed that the decline of the permeation flux in the PAFO tests was more severe at elevated feed pressures as a result of the dense and compacted fouling layer inside the SL.

(A)

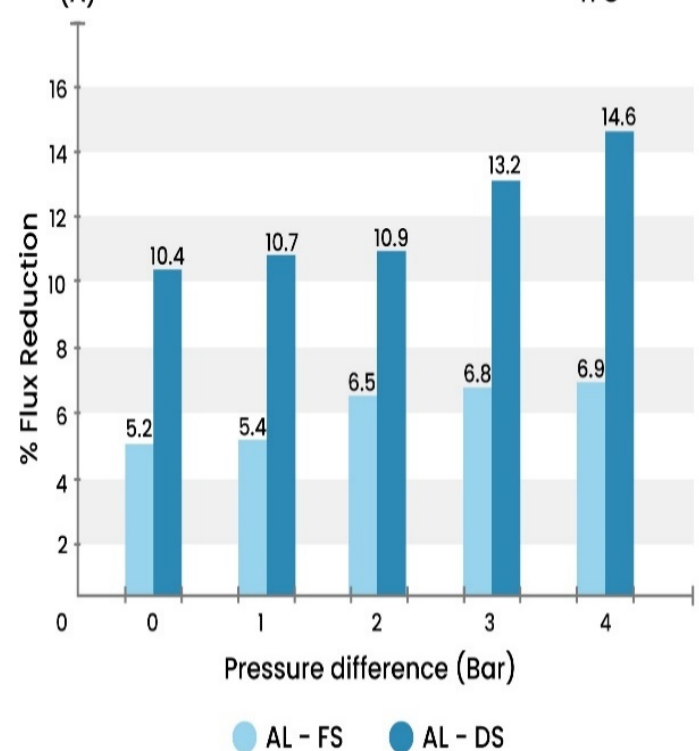

(B)

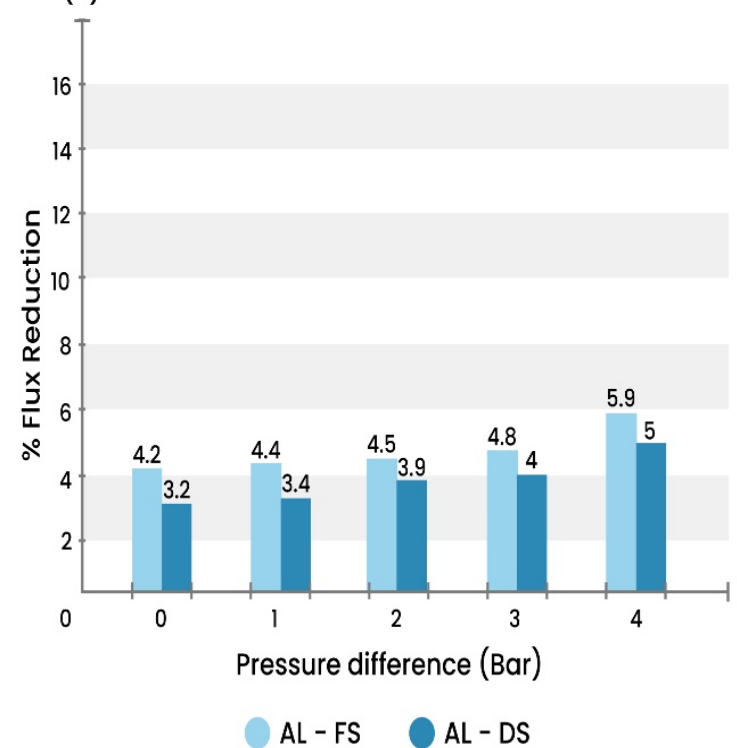

Figure 7. Flux reduction in the FO process at different applied pressures using (A) TFC membrane and (B) CTA membrane in both AL-FS and AL-DS orientations.

Similarly, for the CTA membrane, Figure 7B shows that permeation flux reduction was greater at 4 bar feed pressure. In contrast, the TFC membrane exhibited a greater reduction in the permeation flux in comparison with the CTA membrane (Figure 7B). The highest recorded permeation flux reduction was $5.9 \%$ in the FO mode operating at 4 bar feed pressure; this is about $15 \%$ less than the reduction in the permeation flux in the TFC membrane tested under the same working conditions. The decline in the permeation flux in the CTA working in the AL-DS direction was three times less than that recorded in the TFC membrane under the same operating conditions. On the contrary, CTA membrane 
demonstrated a lower decline in the permeation flux when it was tested in the AL-DS direction. For example, the reduction in the permeation flux at 0 bar feed pressure was $3.2 \%$ in the AL-DS direction and $4.2 \%$ in the AL-FS direction. The corresponding results at 4 bar feed pressure were $5 \%$ in the AL-DS direction and 5.9\% in the AL-FS direction.

The reason for a lower permeation flux reduction in the CTA membrane when the FS was opposite to the SL and experiments with the DS opposite to the SL is attributed to the combined effects of permeation flux in the membrane and the turbidity of FS and DS. The fouling layer was probably denser and compacted when the DS was against the SL due to the accumulation of the fouling materials from the high turbidity DS ( $2.43 \mathrm{NTU})$ in the porous SL. Unfortunately, low permeation flux in the CTA membrane aggravates the problem since fouling materials would not be washed away from the membrane surface by the permeation flow, especially in the AL-FS mode. For this reason, cleaning with DI water was not effective for removing the fouling layer accumulated inside the dense $\mathrm{SL}$ of the membrane operating in the AL-FS direction. Accordingly, the CTA membrane performed better in the AL-DS direction due to the greater permeation flux (Figure 5B) while maintaining a lower reduction in the permeation flux. On the contrary, FO mode is the desirable working mode of the TFC membrane because of the high efficiency of the cleaning method in maintaining a low permeation flux reduction. For TFC membrane, permeation flux in the AL-FS mode at 4 bar feed pressure is almost twice that in the CTA membrane under same operating conditions.

SEM images (Figure 8) reveals that the CTA membrane is more responsive to cleaning by DI water than the TFC membrane. A notable change in the morphology of the active and the support layer of used and washed Porifera TFC and $\mathrm{FTSH}_{2} \mathrm{O}$ CTA membranes. For TFC membrane, cleaning with DI water achieved partial removal of fouling materials from the membrane active while it was less successful in the removal of fouling layer on the support layer side. Ineffective cleaning with DI water of the TFC membrane explains the high reduction of permeation flux after cleaning. In contrast, cleaning with DI water was more effective in washing the fouling layer off the surface of the CTA membrane. The latter showed little fouling materials left on the washed active layer, and fouling materials became sparse after washing. These results explain the lower reduction in the permeation flux of the CTA membrane obtained after washing.

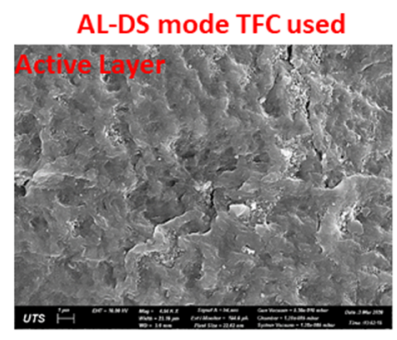

AL-DS mode CTA used

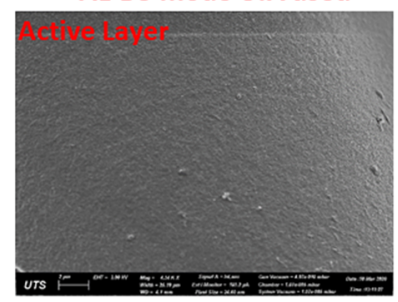

AL-DS mode CTA washed

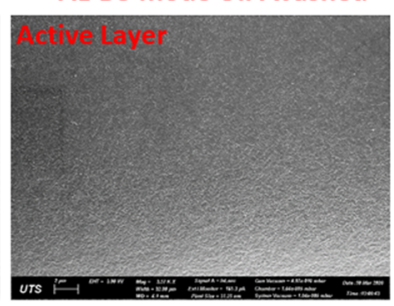

AL-DS mode TFC washed

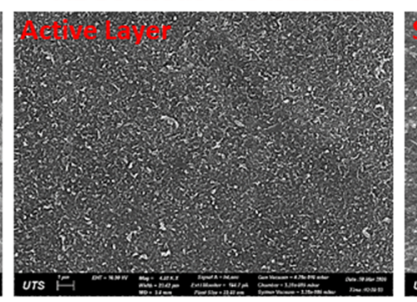

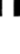

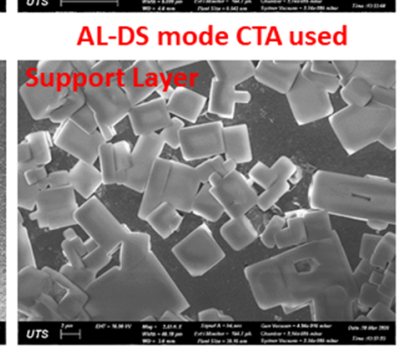

AL-DS mode TFC used

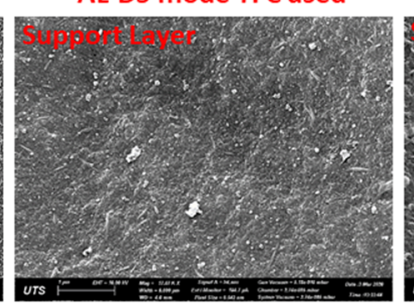

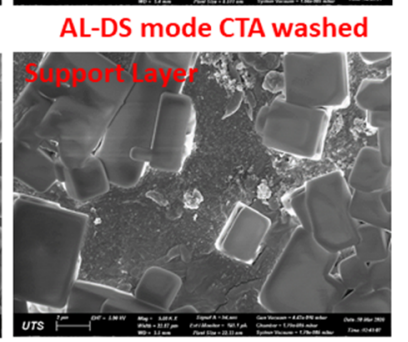

AL-DS mode TFC washed

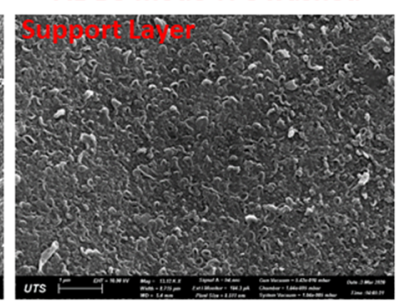

Figure 8. SEM images of the active and support layer of used and washed TFC and CTA membranes. Images show fouling layer in the active and support layer of the membranes used in the FO process conducted with 2 bar hydraulic pressure. 


\subsubsection{Recovery Rate}

The recovery rate is estimated as the ratio of permeate flow to the feed flow according to the following expression:

$$
\operatorname{Re}=\frac{Q_{p}}{Q_{f}} 100 \%
$$

where, $Q_{p}$ and $Q_{f}$ are the flow rate of permeate and FS (L/min), respectively. Results, in general, show that the water recovery rate was higher in the AL-DS orientation due to the greater permeation flux. Figure 9 also revealed that the recovery rate in the FO process was greater at 4 bar feed pressure. The TFC membrane achieved higher recovery rates than the CTA membrane due to higher membrane permeability and thinner structure parameter, which lessened the impact of CP inside the support layer (Table 1). The TFC membrane achieved the highest recovery rate of $11.48 \%$ at 4 bar feed pressure in the AL-DS direction (Figure 9A). As for the CTA membrane, the highest recovery rate was $10.05 \%$ in the PRO mode at 4 bar (Figure 9B). Changing the orientation of the membrane from the AL-FS to the AL-DS orientation, led to more than $50 \%$ increase in the recovery rate. The increase in the recovery rate could be attributed to the greater permeation flux and low ICP. When it is compared with the CTA membrane, TFC membrane achieved greater permeation flux and recovery rate at 4 bar feed pressure. The desirable operating mode for the TFC membrane is the AL- FS direction since such a membrane orientation assures lower permeation flux reduction after cleaning with a DI water only (Figure 7A). For the TFC membrane, results in Figure 7A shows that $93.1 \%$ of the permeation flux was recovered in the FO test at 4 bar while $94.8 \%$ of the permeation flux was recovered in the FO tests at 0 bar. However, the latter operating conditions resulted in $\sim 66 \%$ lower permeation flux in comparison with the FO process at 4 bar. Therefore, the FO process performed better in the AL-FS mode at 4 bar feed pressure using TFC membranes.
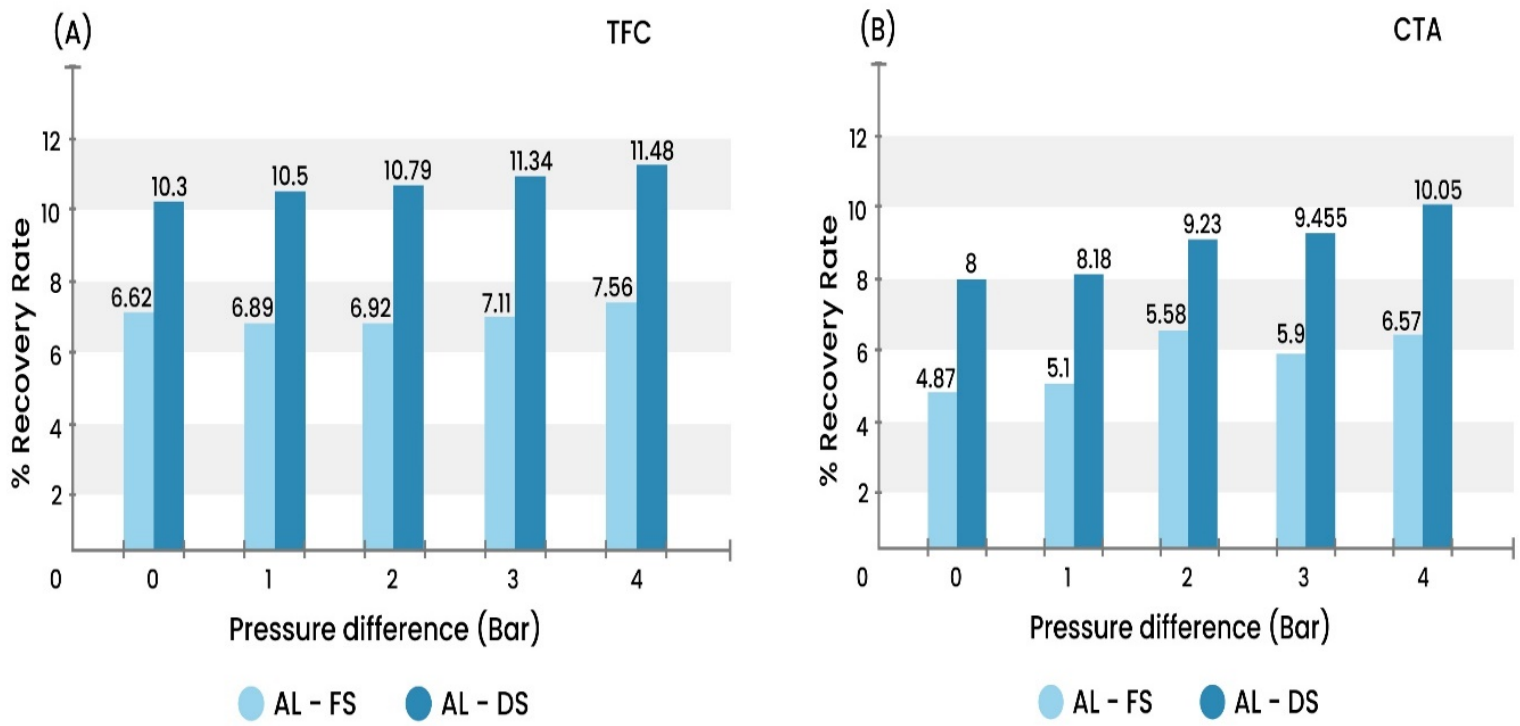

Figure 9. Recovery rate (\%) of FO process at different applied pressures, using TFC membrane (A) and CTA membrane (B), in AL-FS and AL-DS orientations.

\subsection{The Concentration of Divalent Ions}

It is discussed in the literature that the decrease in the concentration of the scale causing divalent ions will minimize the formation and deposition of non-alkaline scale on the surface of heat exchangers tubes [18]. It is important to mention that ion reduction is the decrease in the concentration of divalent ions in the DS after the pretreatment using FO process. As mentioned earlier, the concentration of $\mathrm{Mg}^{2+}, \mathrm{Ca}^{2+}$, and $\mathrm{SO}_{4}{ }^{2-}$ in the 
DS was measured before and after each FO test to record the concentrations after the FO pretreatment. All the ions' concentrations were reported and the percentage of reduction of the ions under different operational parameters is presented separately in Figure 10.
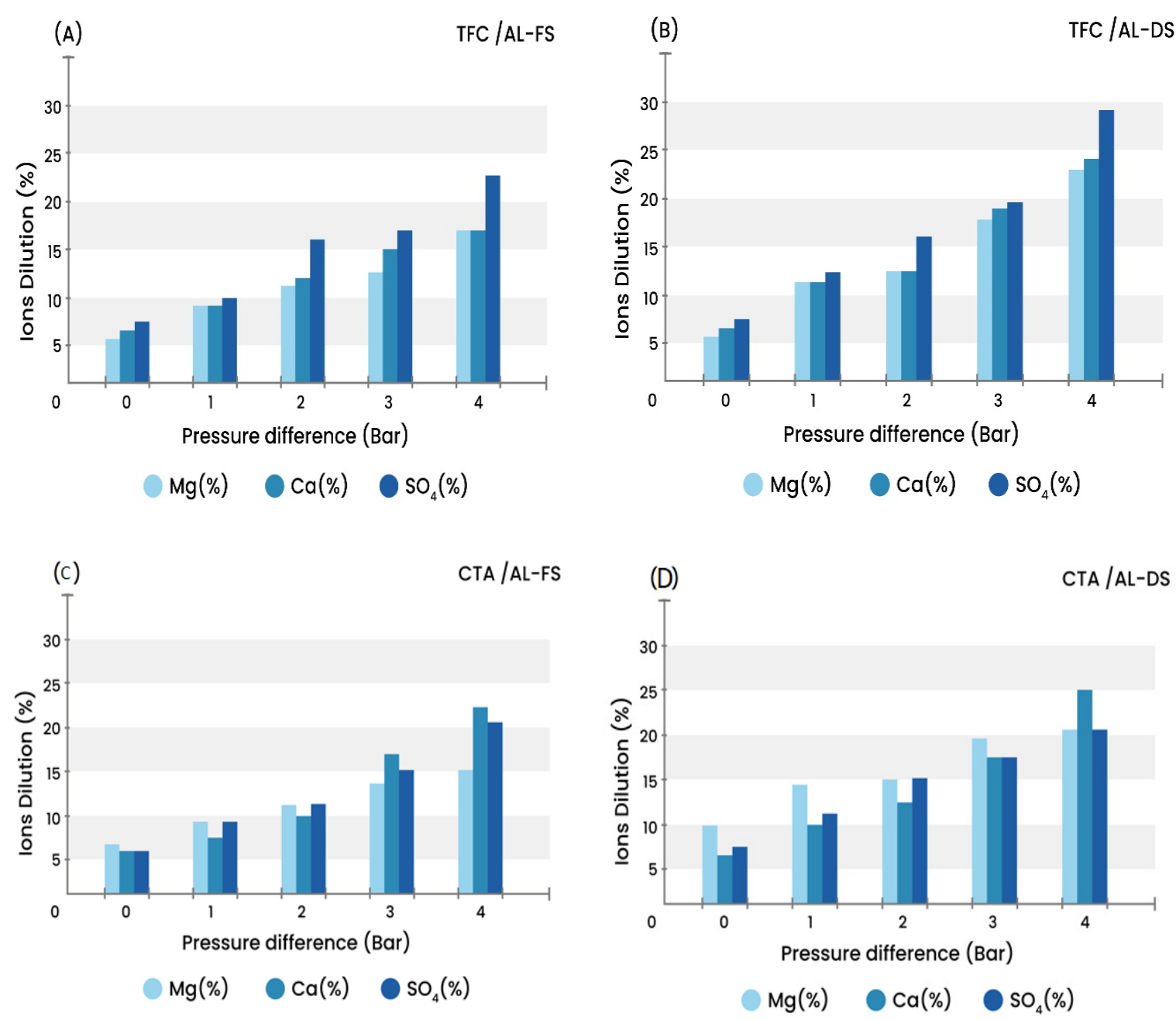

Figure 10. $\mathrm{Mg}^{2+}, \mathrm{Ca}^{2+}$, and $\mathrm{SO}_{4}{ }^{2-}$ dilution in the DS following FO process at different applied pressures and in FO and PAFO mode using TFC and CTA FO membranes. (A,B) TFC membrane in AL-FS and AL-DS orientations, respectively. (C,D) CTA membrane in AL-FS and AL-DS orientations, respectively.

At first sight, results reveal that applying ascending feed pressure led to an increasing permeation flux and dilution of the DS. Comparing to the FO process at 0 bar, up to a four-time higher dilution of the DS was achieved by increasing the feed pressure from 1 to 4 bar. For example, $6 \%$ dilution of $\mathrm{Mg}^{2+}$ was achieved by the TFC membrane at 0 bar but $\mathrm{Mg}^{2+}$ dilution increased to $23 \%$ at 4 bar, that is 4 times more than that at 0 bar. For $\mathrm{Ca}^{2+}, 7 \%$ and $24 \%$ dilution was achieved at 0 and 4 bar, respectively, and for $\mathrm{SO}_{4}{ }^{2-}, 9 \%$ and $28 \%$ dilution was achieved at 0 and 4 bar, respectively. There is also a slight increase in the dilution of ions when the membrane was operating in the AL-DS (Figure 10B) direction in comparison with the AL-FS direction (Figure 10A) due to the higher permeation flow. Furthermore, the TFC membrane showed a more substantial decrease in the divalent ions due to the higher permeation flux and ions rejection rate. Moreover, it is noticeable that for $\mathrm{SO}_{4}{ }^{2-}$, the reduction is the highest amongst all other divalent ions, and this was attributed to its high rejection by the TFC membrane. When the CTA membrane was operating in the AL-DS direction (Figure 10D), the dilution of $\mathrm{Mg}^{2+}$ was $10 \%$ and $21 \%$ at 0 and 4 bar, respectively. The dilution of $\mathrm{Ca}^{2+}$ was $6 \%$ and $25 \%$ at 0 and 4 bar, respectively and it was $7 \%$ and $21 \%$ for $\mathrm{SO}_{4}{ }^{2-}$ at 0 and 4 bar, respectively. It is noteworthy that the recovery rate of 
the MSF plant operating at output gain ratio (GOR) of 8 is about 14\% [32] and hence the minimum ions dilution in the FO process should be $14 \%$ of more. The $14 \%$ divalent ions dilution by the FO process was achieved in the FO process with TFC and CTA membranes operating at 3 bar and 4 bar. Therefore, the PAFO process is effective in scale reduction using CTA and TFC membranes. Furthermore, according to the data gathered about ion reductions, it is important to mention that applying 4 bar in the TFC test with AL-FS mode is promising in seawater pretreatment to the MSF plant due to the considerable decrease in the divalent ions and low permeation flux reduction (Figure 7A).

\subsection{Power Consumption}

Mathematically, specific power consumption $\left(E s-\mathrm{kWh} / \mathrm{m}^{3}\right)$ can be estimated from the expression below:

$$
E_{S}=\frac{P_{f} Q_{f}+P_{D} Q_{D}}{n Q_{p}}
$$

where, $P_{f}$ is the hydraulic pressure on the FS side (bar), $P_{D}$ is the hydraulic pressure on DS side (bar), $Q_{f}$ represents the FS flow rate $\left(\mathrm{m}^{3} / \mathrm{h}\right), Q_{D}$ represents the DS flow rate $\left(\mathrm{m}^{3} / \mathrm{h}\right), n$ represents the efficiency of the pump ( 0.8 in this study), and $Q_{p}$ is the flow rate of permeate $\left(\mathrm{m}^{3} / \mathrm{h}\right)$.

As shown in Figure 11, Es increased when the feed pressure was 4 bar. The results show that $E s$ the in PAFO tests was higher than the Es in the FO tests. However, it is still low compared to the Es required for seawater desalination by the RO technology [32]. The highest specific power consumption was $0.1 \mathrm{kWh} / \mathrm{m}^{3}$ in the TFC membrane operating at 4 bar and in the FO mode. Results also show that the amount of power consumed in the AL-FS orientation is slightly higher when it is compared with that of the AL-DS direction. For example, the Es in the CTA membrane at 4 bar was 0.08 in the AL-FS orientation and $0.1 \mathrm{kWh} / \mathrm{m}^{3}$ in the AL-DS direction (Figure 11B). The corresponding values in the TFC membrane at 4 bar, were 0.053 in the AL-FS mode and $0.065 \mathrm{kWh} / \mathrm{m}^{3}$ in the AL-DS orientation (Figure 11A). According to Equation (3), the lower permeation flow in the AL-FS orientation in comparison with the AL-DS orientation caused a slight increase in power consumption. Results show that the highest $E s$ in the FO pretreatment process is $0.1 \mathrm{kWh} / \mathrm{m}^{3}$ whereas it is close to $2.5 \mathrm{kWh} / \mathrm{m}^{3}$ in the RO technology for seawater desalination [32]. For the desirable operating condition with TFC membrane in the FO mode and at 4 bar, the specific power consumption was $0.065 \mathrm{kWh} / \mathrm{m}^{3}$; this low power consumption underlines the great potential for applying the $\mathrm{FO}$ technology as a pretreatment process of seawater to the thermal MSF plant.
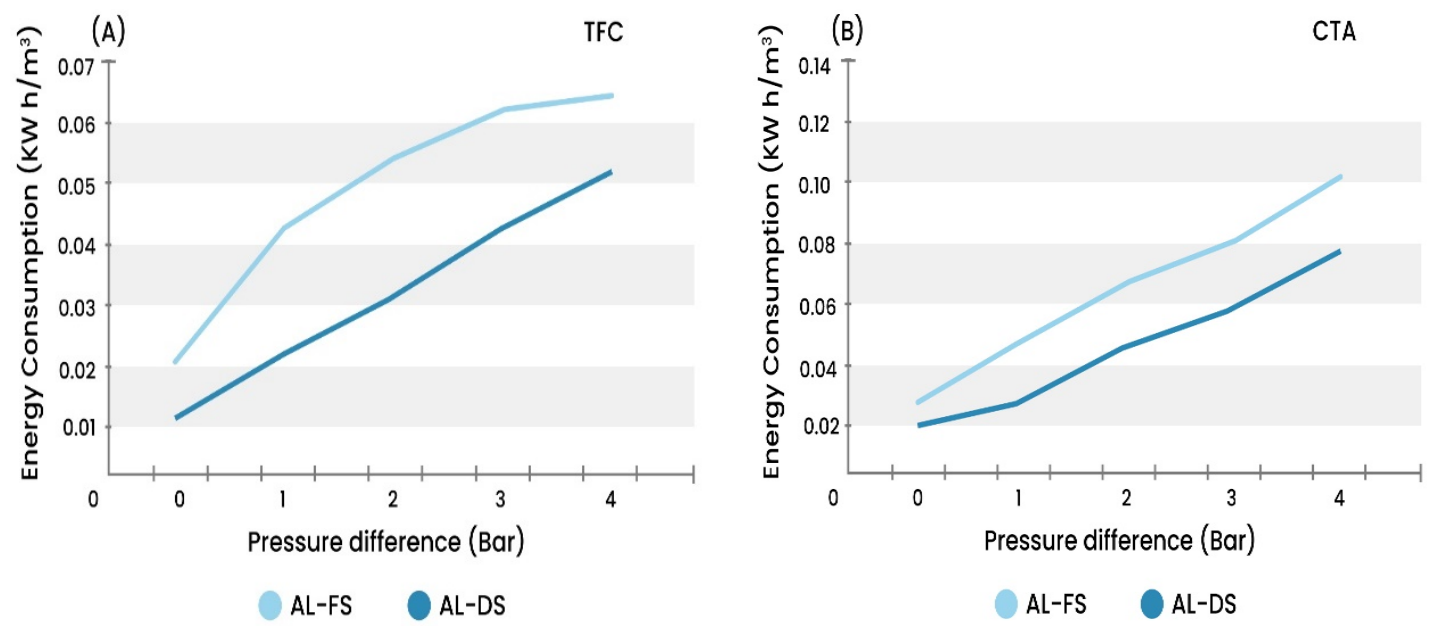

Figure 11. Energy consumption at different applied pressures, (A) using TFC membrane and (B) using CTA membrane. 


\section{Conclusions}

FO and PAFO processes were tested for the pretreatment of seawater using commercial TFC and CTA membranes. The results showed that applying a small hydraulic pressure of the FS side led to an increase in the permeation flux. The permeation flux increased from 7.4 to $14.9 \mathrm{~L} / \mathrm{m}^{2} \mathrm{~h}$ by increasing the feed pressure up to 4 bar in the PAFO process with TFC membrane in the FO mode and at 4 bar. This significant improvement in permeation flux was achieved at a relatively trivial specific power consumption of $0.06 \mathrm{kWh} / \mathrm{m}^{3}$. The CTA membrane, in general, demonstrated lower permeation flux than the TFC at 4 bar pressure, $10.9 \mathrm{~L} / \mathrm{m}^{2} \mathrm{~h}$, but the specific power consumption was slightly higher than that in the TFC membrane, $0.1 \mathrm{kWh} / \mathrm{m}^{3}$.

Interestingly, the recovery of permeation flux in the fouled CTA after cleaning is higher than that in the TFC, and this was due to the characteristics of the fouling layer, which is loosely compacted due to the low permeation flux. Based on its low power consumption and high permeation flux, PAFO process at 4 bar using TFC membrane in the FO mode would be the preferable operating conditions. The latter operating condition has considerable permeation flux recovery of $93 \%$ after DI water cleaning. The results reveal the great potential and feasibility of PAFO process for improving the performance of seawater pretreatment for MSF plant without compromising the advantage of low power consumption.

Author Contributions: D.K.: conceptualization, methodology, writing-original, data curation, investigation. S.Y.: emthodology, data curation, formal analysis. N.G.: data curation, formal analysis, investigation. A.A.: conceptualization, methodology, writing-review and editing, data curation, investigation, supervision, resources, funding acquisition. J.Z.: writing—review and editing, supervision, data analysis. A.H.H.: funding acquisition, investigation, methodology, resources, visualization All authors have read and agreed to the published version of the manuscript.

Funding: This research received no external funding.

Institutional Review Board Statement: Not applicable.

Informed Consent Statement: Not applicable.

Data Availability Statement: Not applicable.

Acknowledgments: This publication was supported by NPRP grant 10-0117-170176 from the Qatar National Research Fund (a member of Qatar Foundation).

Conflicts of Interest: The authors declare no conflict of interest.

\section{References}

1. Intelligence, G.W.; Yearbook, I.D.; Summit, G.W.; Card, R. Global Water Intelligence. Glob. Water Intell. 2011, 12, 1-72.

2. Yadav, S.; Saleem, H.; Ibrar, I.; Naji, O.; Hawari, A.A.; Alanezi, A.A.; Zaidi, S.J.; Altaee, A.; Zhou, J. Recent developments in forward osmosis membranes using carbon-based nanomaterials. Desalination 2020, 482, 114375. [CrossRef]

3. Gilron, J. Water-energy nexus: Matching sources and uses. Clean Technol. Environ. Policy 2014, 16, 1471-1479. [CrossRef]

4. Al-Karaghouli, A.; Kazmerski, L.L. Energy consumption and water production cost of conventional and renewable-energypowered desalination processes. Renew. Sustain. Energy Rev. 2013, 24, 343-356. [CrossRef]

5. Nassrullah, H.; Anis, S.F.; Hashaikeh, R.; Hilal, N. Energy for desalination: A state-of-the-art review. Desalination 2020, 491, 114569. [CrossRef]

6. Qasim, M.; Badrelzaman, M.; Darwish, N.N.; Darwish, N.A.; Hilal, N. Reverse osmosis desalination: A state-of-the-art review. Desalination 2019, 459, 59-104.

7. Mabrouk, A.N.A. Technoeconomic analysis of once through long tube MSF process for high capacity desalination plants. Desalination 2013, 317, 84-94. [CrossRef]

8. Yadav, S.; Ibrar, I.; Bakly, S.; Khanafer, D.; Altaee, A.; Padmanaban, V.; Samal, A.K.; Hawari, A.H. Organic Fouling in Forward Osmosis: A Comprehensive Review. Water 2020, 12, 1505. [CrossRef]

9. Hassan, A. Fully Integrated NF-Thermal Seawater Desalination Process and Equipment. Google Patents US20060157410A1, 20 July 2006.

10. El Din, A.S.; El-Dahshan, M.; Mohammed, R. Inhibition of the thermal decomposition of $\mathrm{HCO}_{3}{ }^{-}$A novel approach to the problem of alkaline scale formation in seawater desalination plants. Desalination 2002, 142, 151-159. [CrossRef] 
11. Lyster, E.; Kim, M.-m.; Au, J.; Cohen, Y. A method for evaluating antiscalant retardation of crystal nucleation and growth on RO membranes. J. Membr. Sci. 2010, 364, 122-131. [CrossRef]

12. Altaee, A.; Mabrouk, A.; Bourouni, K.; Palenzuela, P. Forward osmosis pretreatment of seawater to thermal desalination: High temperature FO-MSF/MED hybrid system. Desalination 2014, 339, 18-25. [CrossRef]

13. Thabit, M.S.; Hawari, A.H.; Ammar, M.H.; Zaidi, S.; Zaragoza, G.; Altaee, A. Evaluation of forward osmosis as a pretreatment process for multi stage flash seawater desalination. Desalination 2019, 461, 22-29. [CrossRef]

14. Li, L.; Shi, W.; Yu, S. Research on forward osmosis membrane technology still needs improvement in water recovery and wastewater treatment. Water 2020, 12, 107. [CrossRef]

15. Lee, S. Performance Comparison of Spiral-Wound and Plate-and-Frame Forward Osmosis Membrane Module. Membranes 2020, 10, 318. [CrossRef]

16. Chung, T.-S.; Zhang, S.; Wang, K.Y.; Su, J.; Ling, M.M. Forward osmosis processes: Yesterday, today and tomorrow. Desalination 2012, 287, 78-81. [CrossRef]

17. Mazlan, N.M.; Marchetti, P.; Maples, H.; Gu, B.; Karan, S.; Bismarck, A.; Livingston, A.G. Organic fouling behaviour of structurally and chemically different forward osmosis membranes-a study of cellulose triacetate and thin film composite membranes. $J$. Membr. Sci. 2016, 520, 247-261. [CrossRef]

18. Hawari, A.H.; Kamal, N.; Altaee, A. Combined influence of temperature and flow rate of feeds on the performance of forward osmosis. Desalination 2016, 398, 98-105. [CrossRef]

19. Oh, Y.; Lee, S.; Elimelech, M.; Lee, S.; Hong, S. Effect of hydraulic pressure and membrane orientation on water flux and reverse solute flux in pressure assisted osmosis. J. Membr. Sci. 2014, 465, 159-166. [CrossRef]

20. Blandin, G.; Verliefde, A.R.; Tang, C.Y.; Childress, A.E.; Le-Clech, P. Validation of assisted forward osmosis (AFO) process: Impact of hydraulic pressure. J. Membr. Sci. 2013, 447, 1-11. [CrossRef]

21. Coday, B.D.; Heil, D.M.; Xu, P.; Cath, T.Y. Effects of transmembrane hydraulic pressure on performance of forward osmosis membranes. Environ. Sci. Technol. 2013, 47, 2386-2393. [CrossRef]

22. Jamil, S.; Jeong, S.; Vigneswaran, S. Application of pressure assisted forward osmosis for water purification and reuse of reverse osmosis concentrate from a water reclamation plant. Sep. Purif. Technol. 2016, 171, 182-190. [CrossRef]

23. Van der Bruggen, B.; Luis, P. Forward osmosis: Understanding the hype. Rev. Chem. Eng. 2015, 31, 1-12. [CrossRef]

24. Ibrar, I.; Yadav, S.; Altaee, A.; Samal, A.K.; Zhou, J.L.; Nguyen, T.V.; Ganbat, N. Treatment of biologically treated landfill leachate with forward osmosis: Investigating membrane performance and cleaning protocols. Sci. Total Environ. 2020, $744,140901$. [CrossRef]

25. Blandin, G.; Vervoort, H.; Le-Clech, P.; Verliefde, A.R. Fouling and cleaning of high permeability forward osmosis membranes. J. Water Process Eng. 2016, 9, 161-169. [CrossRef]

26. Madsen, H.T.; Nissen, S.S.; Muff, J.; Søgaard, E.G. Pressure retarded osmosis from hypersaline solutions: Investigating commercial FO membranes at high pressures. Desalination 2017, 420, 183-190. [CrossRef]

27. Yadav, S.; Ibrar, I.; Altaee, A.; Déon, S.; Zhou, J. Preparation of novel high permeability and antifouling polysulfone-vanillin membrane. Desalination 2020, 496, 114759. [CrossRef]

28. Zhang, S.; Wang, P.; Fu, X.; Chung, T.-S. Sustainable water recovery from oily wastewater via forward osmosis-membrane distillation (FO-MD). Water Res. 2014, 52, 112-121. [CrossRef]

29. Tang, C.Y.; She, Q.; Lay, W.C.; Wang, R.; Fane, A.G. Coupled effects of internal concentration polarization and fouling on flux behavior of forward osmosis membranes during humic acid filtration. J. Membr. Sci. 2010, 354, 123-133. [CrossRef]

30. Xu, Y.; Peng, X.; Tang, C.Y.; Fu, Q.S.; Nie, S. Effect of draw solution concentration and operating conditions on forward osmosis and pressure retarded osmosis performance in a spiral wound module. J. Membr. Sci. 2010, 348, 298-309. [CrossRef]

31. Hawari, A.H.; Al-Qahoumi, A.; Ltaief, A.; Zaidi, S.; Altaee, A. Dilution of seawater using dewatered construction water in a hybrid forward osmosis system. J. Clean. Prod. 2018, 195, 365-373. [CrossRef]

32. McGovern, R.K. On the potential of forward osmosis to energetically outperform reverse osmosis desalination. J. Membr. Sci. 2014, 469, 245-250. [CrossRef] 